\title{
Sexual Assault Training in the Military: Evaluating Efforts to End the "Invisible War"
}

\author{
Kathryn J. Holland • Verónica Caridad Rabelo • \\ Lilia M. Cortina
}

Published online: 3 September 2014

(c) Society for Community Research and Action 2014

\begin{abstract}
Sexual assault is an insidious problem in the United States military. In 2005 the Department of Defense (DoD) created the Sexual Assault Prevention and Response Office, which centralizes responsibility for sexual assault training. However, this training initiative has undergone little evaluation by outside researchers. Addressing this need, we analyzed responses from over 24,000 active duty personnel who completed the 2010 DoD Workplace and Gender Relations Survey. We assessed whether sexual assault training exposure (None, Minimal, Partial, or Comprehensive) predicted accurate knowledge of sexual assault resources and protocols. Using a social-ecological framework, we investigated whether institutional and individual factors influenced Service members' training exposure and judgment of training effectiveness. According to our results, exposure to comprehensive training predicted lower sexual assault incidence and superior knowledge. However, comprehensive training differed as a function of military branch, rank, gender, and sexual assault history. Judgments of training effectiveness also varied across these dimensions. Our results highlight the importance of considering context, gender, and victimization history when evaluating institutional efforts to end sexual violence. The DoD's 2010 annual report on military sexual assault concluded that "most Active Duty members receive effective training on sexual assault" (p. 104). Our results cast doubt on that assertion.
\end{abstract}

Keywords Workplace violence $\cdot$ Sexual assault $\cdot$ Military sexual trauma - Military · Training · Program evaluation

K. J. Holland $(\bowtie)$ V. C. Rabelo · L. M. Cortina Departments of Psychology and Women's Studies, University of Michigan, 530 Church Street, Ann Arbor, MI 48109-1043, USA e-mail: kahollan@umich.edu
Pentagon officials can tell you exactly how many tanks and Humvees the new C-17 "Globemaster III" can carry. They can tell you the height, weight and speed of every airplane and ship... But ask them how many military women have been attacked by servicemen and their statistical wizardry vanishes. (Pardue and Moniz 1996, p. A8)

Sexual violence is alarmingly common in the militaryespecially against female personnel. As former California Democratic Representative Jane Harman (2008) testified, "a woman who signs up to protect her country is more likely to be raped by a fellow soldier than killed by enemy fire." This problem has reached such proportions that it has been dubbed an "invisible war" (Ziering et al. 2012). Studies estimate that 9-13\% of Service women and 1-2\% of Service men endure sexual assault per year of military employment (Bostock and Daley 2007; Lipari et al. 2008; Street et al. 2008). These figures likely represent conservative estimates, with sexual assault being the most underreported act of violence in the U.S. (Bachman and Taylor 1994; Kilpatrick et al. 1992). The Armed Services number almost 1.5 million personnel (Defense Manpower Data Center 2013b), making this a type of workplace violence with enormous scope. The Department of Defense (DoD) knows there is a problem, which begs the question: what is being done about it?

The current study makes important contributions by examining the DoD's sexual assault training efforts. More specifically, we test whether this prevention and education program achieves one of its fundamental goals: fostering accurate knowledge about sexual assault resources and protocols among active duty personnel. Drawing from a social-ecological framework, we also investigate influences of institutional and individual factors on training exposure 
and effectiveness (operationalizing "effectiveness" with measures developed by the military). Using data collected by the DoD, we reach conclusions that diverge from military conclusions. More specifically, we find that military sexual assault training is often lacking in content and efficacy-especially in the eyes of personnel for whom it is most relevant (e.g., those who are at greatest risk of sexual assault).

\section{Sexual Assault in a Military Context}

Members of the Armed Services, especially women, are at greater risk for encountering sexual assault than civilians (Bostock and Daley 2007), and aspects of military culture help explain this trend. With its history of excluding women from full participation (e.g., combat), the U.S. military is a hypermasculine, male-dominated institution. As of the year 2009 , the approximately 198,000 women serving in the military could access $92 \%$ of all specialties, yet occupied just $14.3 \%$ of positions available to them (Department of Defense 2009). The idealized soldier is tough, fearless, and unwavering; this image is more in line with stereotypical masculinity (e.g., assertive, strong) than femininity (e.g., sensitive, fragile; Spence and Helmreich 1980). When stereotypes associated with a certain group (e.g., women) clash with stereotypes linked to a particular role (e.g., combat), this fuels unfavorable biases toward members of that group (Eagly and Karau 2002; Heilman and Eagly 2008). These negative expectations translate into negative treatment. In the words of Army Sergeant Sarah Scully, "In the army, any sign that you are a woman means that you are automatically ridiculed and treated as inferior" (quoted in Benedict 2010, p. 5). Ultimately, we argue that mismatches between gender stereotypes and job roles set the stage for personal and professional penalties for military women, ranging from shortened career ladders to derisive comments to physical punishment in the form of sexual assault.

Experiencing sexual assault can be psychologically devastating, and this is especially true in the military ecological context. According to Benedict (2010),

From the victim's point of view, rape is torture because it is a painful and violent attack on the most intimate part of your body and an attempt to destroy your dignity and autonomy. Rape and sexual assault by someone on whom you depend-whether a parent, partner, or comrade-in-arms-is more traumatizing than assault by anyone else. (p. 6)

Survivors of military sexual trauma must often reside and work alongside their assailants, increasing the distress associated with the assault experience (Bell and Reardon 2011; Defense Manpower Data Center 2013a). Service members who have been sexually assaulted must contend with competing messages from military training (i.e., you should rely unconditionally upon fellow troop membersyour life may depend on it) versus assault encounters (i.e., you cannot trust fellow troop members-to do so risks violent attack). Finally, the stereotypes associated with the idealized Service member (e.g., strength, powerfulness) contrast with the assault survivor experience (e.g., feelings of helplessness and violation; Bell and Reardon 2011).

Given these aspects of military context, it is unsurprising that military sexual assault has adverse consequences for mental health. Both female and male survivors of military sexual trauma are more likely to report general psychological distress, anxiety, depression, eating disorders, sexual dysfunction, sleep disturbances, alcohol dependence, drug abuse, suicidal ideation, and self-harm (Harned et al. 2002; Kimerling et al. 2007; Martin et al. 2000). Survivors of military sexual assault report greater likelihood of developing posttraumatic stress disorder (PTSD; Kang et al. 2005; Surís et al. 2004). Physiological consequences of sexual trauma include chronic health issues (Kimerling et al. 2007; Sadler et al. 2000), perceptions of health dissatisfaction (Harned et al. 2002), as well as negative physiological health in general (Martin et al. 2000). Survivors of military sexual assault are also less likely to report satisfaction with their work and coworkers; in turn, these job attitudes are associated with poorer organizational commitment and workgroup productivity (Harned et al. 2002). Collectively, this research illustrates that the distress associated with undergoing sexualized violence is distinct from other forms of military trauma (Fontana and Rosenheck 1998), and that experiencing sexual assault while on active duty is detrimental to Service members' professional, psychological, and physical health. Campbell et al. (2009) theorized that factors at multiple levels of social-ecology contribute to sexual assault experiences and outcomes. For example, individual-level factors (e.g., sociodemographics), meso/exosystem factors (e.g., institutional structure), and macrosystem factors (e.g., cultural norms) all play an important role in determining survivors' experiences after an assault and perpetuating a rape-prone culture (Campbell et al. 2009). Following this work, a social-ecological model of military sexual assault, and its impact upon the larger community, would consider the interplay among individual factors (e.g., gender, sexual assault survivorship), institutional factors (e.g., Service branch, military hierarchy), and the broader context (e.g., the uniqueness of military culture).

\section{Institutional Response to Military Sexual Assault}

Despite the breadth of research documenting the incidence and impact of military sexual assault, leadership in the Armed 
Forces has been slow to take action. One of the most visible military scandals took place at the 1991 Tailhook Association symposium (Tailhook Association, n.d.). Over the course of five days, eighty-three women and seven men endured sexual assault and harassment during the convention meeting. Many of these victims reported their abuse, yet no punitive measures were taken. Over the past twenty years, military officials have responded to sexual assault crimes on a case-by-case basis.

Not until 2005 did the DoD identify a critical need for organization-wide reform. That year marked the creation of the Sexual Assault Prevention and Response Office (SAPRO) to serve as the central point of responsibility and resources for military sexual assault (Department of Defense 2010; see also Department of Defense Sexual Assault Prevention and Response Office, n.d.). According to the Department of Defense (2010), this new Office "requires each Military Service to maintain its own SAPR program, document both Restricted [a confidential option that does not result in an official investigation] and Unrestricted Reports of sexual assault, investigate Unrestricted Reports of sexual assault, and hold subjects appropriately accountable" (p. 1). In other words, the SAPRO oversees each military branch, and in turn, each branch is responsible for training personnel about sexual assault policies, reporting procedures, and resources. These trainings aim to educate Service members about sexual assault (and what to do if an assault occurs) and prevent its occurrence.

To evaluate institutional climate and policy effectiveness, the DoD conducts a large survey of all active duty personnel-the Workplace and Gender Relations Survey of Active Duty Members (WGRA) about every 4 years (e.g., 1998; 2002; 2006; 2010). The 2006 WGRA added more detailed questions about experiences of "unwanted sexual contact" in the military, defined as "intentional sexual contact that was against a person's will or which occurred when the person did not or could not consent" (Defense Manpower Data Center 2013a, p. 1). In 2008, the U.S. Government Accountability Office (GAO) urged the military to evaluate the effectiveness of its sexual assault training program, and the 2010 WGRA included items assessing Service members' experiences and perceptions of sexual assault training. For example, items asked trainees how effective the training was at preventing sexual assault and explaining reporting options (i.e., restricted/unrestricted). Using these data, the DoD's 2010 annual report on sexual assault in the military stated:

Most women and men were positive in their assessment of the effectiveness of their training... Based on this [sic] data, the Department concludes that most Active Duty members receive effective training on sexual assault reporting and the options available to do so. (p. 104)
Other evidence, however, points to flaw in military sexual assault training programs. For example, the SAPRO mandates that all Service members receive periodic sexual assault prevention and response training, but the enforcement and content of such trainings are not consistent across all branches of the military (Defense Manpower Data Center 2013a). Moreover, the DoD has recommended that training "incorporate adult learning theory, which includes group participation and interaction" (Department of Defense 2013, p. 62). However, anecdotal evidence suggests that this often fails to happen; an official DoD report describes that, at about half of all Coast Guard installations surveyed, trainings "relied heavily on power point briefings and... participants were not engaged" (U.S. GAO 2008, p. 26). Moreover, other stakeholders reported that training is not scenario-based, and that many Service members do not pay attention or take the training seriously (Schmid 2010; U.S. GAO 2008). Thus, sexual assault training varies in depth, breadth, and frequency across different levels of military context (e.g., Service branch).

Another flaw involves lack of attention to trainer and trainee demographic composition. Naval trainings, for example, are conducted with both junior and senior personnel. One installation instructed 800 Service members in one sitting (U.S. GAO 2008). Given military culture and hierarchy, such a delivery would not encourage junior trainees to ask clarifying questions or share their opinions (Schmid 2010). The trainers themselves may also affect the quality of training. The coordination and implementation of SAPRO programs largely relies on Commanders and SAPRO Coordinators (U.S. GAO 2012). Recently, there have been several well-publicized instances in which those individuals, whose jobs are to prevent sexual assault and protect survivors, have been charged with sexual assault themselves. For example, a sergeant responsible for sexual assault prevention at Fort Hood is under investigation for sexual assault (USA Today 2013). While this example may not represent the norm, it still calls the DoD's sexual assault training program into question; without systematic evaluation, there is no way to know if these programs are actually useful in this context. The current study takes up this aim.

\section{Current Study: Considering Individual and Institutional Factors}

Existing research on military sexual assault training is not only limited, but also very general. For instance, the DoD's 2010 annual report on sexual assault in the military evaluates training efforts (e.g., via Service members' selfreported judgments of training), but only reports general 
percentages collapsing across categories of military personnel. With this in mind, our first research aim was to examine how training exposure relates to a critical outcome: actual knowledge of sexual assault resources and protocols. We hypothesized that:

H1 Knowledge of sexual assault resources and protocols would increase with exposure to more comprehensive sexual assault training.

Moreover, we examined how training exposure varied by institutional context. Approaches to sexual assault training and prevention differ by Service branch (Department of Defense 2010), and some research suggests that rates of sexual assault may also vary by branch and rank (e.g., Firestone et al. 2012; Harned et al. 2002; Hay and Elig 1999). Thus, it is important to consider contextual and institutional influences on experiences of sexual assault training. However, existing research on military training generalizes across military personnel. For instance, Kelley et al. (2005) examined trainee satisfaction with the Navy's Sexual Assault Victim Intervention (SAVI) training program, but did not report whether or how satisfaction varied among trainee subgroups. Rank, or power within the military, may affect judgments of training. Rigid organizational hierarchies and power imbalances play an important role in military sexual assault (Harned et al. 2002; Morris 1996; Sadler et al. 2003). Lower-ranking military personnel are more likely to actually experience sexual trauma while on active duty (Firestone et al. 2012; Harned et al. 2002), and therefore have more experiential knowledge with which to evaluate their training. On the other hand, higher-ranking personnel may have more knowledge and training on military sexual assault, due to their longer tenure and responsibilities with respect to sexual assault reporting protocols (Hillman 2009; Turchik and Wilson 2010). In the event of experiencing sexual victimization, Enlisted Service members have little latitude to exit the military, whereas Officers do not adhere to these same mandates for obligatory service (Sims et al. 2005). As such, rank is an important individual factor to consider with respect to access to and evaluation of sexual assault training content. Given these competing proposals, and lack of prior research on this issue, we investigated the effects of institutional factors via a research question:

RQ1 Does exposure to sexual assault training vary by Service branch and military rank (enlisted vs. officer)?

In addition, gender and history of sexual assault are two individual-level factors that are important to consider when examining training exposure. The military strives to provide sexual assault training to all Service members, so we did not expect sheer access to training to differ by gender or survivor status. However, women endure more sexual violence than men, in both military and civilian life
(Bostock and Daley 2007); as a result, women may have more knowledge or awareness of sexual assault and/or prior experience with sexual assault policies, reporting procedures, investigations, etc. Studies of sexual assault prevention on college campuses suggest that women often enter training with a more critical outlook on rape than men (Breitenbecher 2000). As a result, men's understanding and attitudes about rape become more similar to that of women after some interventions (Breitenbecher 2000). Moreover, Service members who have experienced military sexual trauma are also more likely to have actually used organizational reporting mechanisms. Research on civilian sexual trauma frequently examines the quality of the legal and medical system via the experiences and perceptions of actual sexual assault survivors (e.g., Campbell 2005, 2006, 2008; Campbell et al. 1999, 2001b; DuMont et al. 2009; Felson and Pare 2008). Greater knowledge of and actual experience with sexual assault may foster more critically evaluative descriptions of training. We hypothesized that:

H2 Women (compared to men) and sexual assault survivors (compared to non-victims) would be more critical of military sexual assault training-evaluating it as less comprehensive in its exposure to important content domains

In addition to considering reports of training exposure, we also investigated perceived training effectiveness, from the perspective of recent trainees. Specifically, how effective was the training at (1) reducing/preventing sexual assault, and (2) explaining the difference between sexual assault reporting options? It is standard practice in the military to use trainee self-report to evaluate the effectiveness of military sexual assault training efforts (e.g., Department of Defense 2010). However, military conclusions about perceived effectiveness have neglected differences across military personnel. Thus, we again examined institutional (Service branch and rank) and individual factors (gender, and sexual assault history) that may influence judgments of training effectiveness. Hypotheses about influences of Service branch or rank on judgments of training effectiveness are difficult to derive. As noted earlier, each branch implements its own sexual assault training. Training effectiveness therefore might differ by branch, but it is unclear how. Lower-ranking military personnel are more likely to experience sexual trauma (Firestone et al. 2012; Harned et al. 2002), so they may have more experience using reporting procedures. Conversely, higher-ranking personnel may have more knowledge of the incidence of sexual assault and reporting procedures, due to chain-of-command protocol for reporting sexual assault (Hillman 2009; Turchik and Wilson 2010). Given the different possibilities with respect to Service branch and rank, we kept this open as another research question: 
RQ2 Do members of different Service branches and ranks (enlisted vs. officer) differ in their evaluations of sexual assault training as effective at (a) reducing/preventing sexual assault, and (b) explaining reporting options?

Despite military efforts to reduce sexual assault, incidence rates remain unacceptably high (Lipari et al. 2008; Street et al. 2008). As stated above, women experience a greater amount of sexual violence in both military and civilian life (Bostock and Daley 2007). As a result, women may be more perceptive of sexual assault (Harris and Miller 2000). Women may also give greater consideration to reporting options, in the event an assault would occur. It is also more likely that Service women and men who have experienced sexual assault would consider or actually utilize reporting procedures. Research on civilian sexual assault suggests that interactions with the medical and legal system can be extremely challenging for victims (Campbell 2005, 2006, 2008; Campbell et al. 1999, 2001a, b; Campbell and Raja 2005; Ullman and Townsend 2007). For example, survivors are often poorly informed or unprepared for navigating the legal system (Ullman and Townsend 2007). Social system personnel (e.g., doctors, police officers) underestimate the impact they are having on the victim, and the ways in which their actions and statements may be confusing or distressing (Campbell 2008). A study of sexual assault help-seeking in the military found that military legal officials often discouraged victims from reporting or refused to accept their reports altogether (Campbell and Raja 2005). In the military, many survivors choose not to formally report their sexual assault experience because they fear disbelief, inaction, or retaliation (Bell and Reardon 2011; Firestone et al. 2012). However, it is possible that lack of knowledge about reporting options or negative experiences interacting with support personnel contributes to reporting attitudes and behaviors. Given these findings, we predicted that both women and sexual assault survivors would evaluate sexual assault training as less "effective." Specifically:

H3 Women (compared to men) and sexual assault survivors (compared to non-victims) would be more critical of military sexual assault training-evaluating it as (a) less effective at reducing/preventing sexual assault, and (b) less effective at explaining reporting options.

In summary, the overarching aim of this project was to evaluate military sexual assault training in several ways. First, we tested whether training exposure predicted actual knowledge of sexual assault resources and protocols. Next, we examined how training exposure varied by institutional (Service branch, rank) and individual (gender, sexual assault history) factors. Finally, we investigated how judgments of training effectiveness differed according to those same factors. All analyses relied on the DoD's own data, collected in the 2010 WGRA.

\section{Method}

Participants and Procedure

The current study was a secondary analysis of data collected by the DoD. Members of the U.S. Military completed the 2010 Workplace and Gender Relations Survey of Active Duty Members (2010 WGRA), which was designed to sample even numbers of individuals across sex/gender, Service branch, and race/ethnicity. The survey was administered online and on-paper to approximately 90,391 active duty members, of whom 26,505 (29.32 \%) offered usable data (Defense Manpower Data Center 2010). For a detailed explanation of survey and sampling procedures, including the complete survey, see Defense Manpower Data Center (DMDC 2010) and Rock et al. (2011). For the current study, we focused on Enlisted members $(n=17,288$, or $70.2 \%)$ and Officers $(n=7,322$, or $29.8 \%$ ). Of this group, there were 15,859 men $(59.8 \%)$ and 10,646 women $(40.2 \%)$. With respect to branch, 6,963 $(26.3 \%)$ were affiliated with the Air Force, 6,703 (25.3\%) were Army soldiers, 2,476 (9.3\%) were Coast Guard personnel, 5,033 (19.0\%) were Marines, and 5,330 $(20.1 \%)$ were members of the Navy.

\section{Measures}

\section{Sex/Gender}

Participants indicated their sex by checking $1=$ male or $2=$ female. If this item was skipped, administrators of the 2010 WGRA used Service members' records to determine their sex. ${ }^{1}$

\section{Service Branch}

Administrators used active duty members' records to determine their Service affiliation (Air Force, Army, Coast Guard, Marine Corps, or Navy).

\footnotetext{
${ }^{1}$ Feminist theorists have long articulated the differences between sex and gender. Gender, as a concept, allows us to differentiate biological/physiological differences between women and men (i.e., sex) from the social roles and characteristics that are assigned to women and men (Delphy 1993; Oakley 1972/1985; Scott 1988). While female/male typically designates "sex," we conceptualize this variable as "gender" in our analyses. Gender, and the social meanings and experiences associated with it, is a more useful category of analysis when examining social structures and phenomena (Scott 1988).
} 


\section{Rank}

Administrators used Service members' record data to determine participants' and paygrade (E1-E3/Unknown Enlisted, E4, E5-E6, E7-E9, W1-W5, O1-O3/Unknown Officers, or $04-06)$. For clarity and ease of interpretation, we collapsed across paygrade levels to create two groups: Enlisted $(1=E 1-E 9)$ and Commissioned Officers $(2=01-O 6)$. We excluded Warrant Officers (W1-W5) from analyses, due to the small size and ambiguous social power of this group.

\section{Sexual Assault Survivor Status}

Participants indicated whether or not they experienced any of five types of sexual assault over the past twelve months of military employment. The measure began with the stem, "Have you experienced any of the following intentional sexual contacts that were against your will or occurred when you did not or could not consent where someone..." (emphasis in original). Behaviors then ranged from unwanted touching to attempted rape to completed rape, e.g., "Sexually touched you (e.g., intentional touching of genitalia, breasts, or buttocks) or made you sexually touch them", "Attempted to make you have sexual intercourse, but was not successful", and "Made you perform or receive oral sex, anal sex, or penetration by a finger or object”). In the dataset, WGRA administrators assigned participants who experienced any of these five behaviors a code of 1 (past-year survivor). All others were assigned a code of 0 (past-year non-victim).

\section{Training Exposure}

Personnel reported whether they had received "any military training during the past 12 months on topics related to sexual assault" (emphasis original), $1=N o$ and $2=$ Yes. Those who responded "yes" completed ten follow-up items about that training. Trainees rated (on a scale from $1=$ strongly disagree to $5=$ strongly agree) the extent to which their training covered a range of different content areas. Sample items included: "Provides a good understanding of what actions are considered sexual assault," "Explains the reporting options available if a sexual assault occurs," and "Teaches how to intervene when you witness a situation involving a fellow Service member (bystander intervention)." Averaging these 10 items into a scale, Cronbach's alpha was .98 .

To check the validity of this training exposure measure, we analyzed two items assessing participants' satisfaction with the information available about restricted and unrestricted reporting procedures for sexual assault (e.g., "How satisfied have you been with the availability of information on how to file an unrestricted report?"). Response options ranged from $1=$ very dissatisfied to $5=$ very satisfied, and the two items were averaged to give a mean satisfaction with the availability of reporting information score.

\section{Knowledge of Sexual Assault Resources and Protocol}

Six dichotomous (either yes/no or true/false) questions assessed participants' knowledge of sexual assault resources (e.g., “I am aware of my installation's Sexual Assault Awareness Month programs") and protocols (e.g., "When you are in a social setting, it is your duty to stop a fellow Service member from doing something potentially harmful to themselves or others"). Responses yes and true were coded as 1 and responses no and false were coded as 0 . These six items were summed to create a single measure of knowledge of resources and protocols (range 0-6); higher scores indicate greater (accurate) knowledge. Each item contains a "correct" answer; thus, this provided an objective measure of employee knowledge.

\section{Judgments of Training Effectiveness}

Two items assessed employee judgments of training effectiveness. The stem read, "In your opinion, how effective was the training you received in..." followed by "Actually reducing/preventing sexual assault or behaviors related to sexual assault" and "Explaining the difference between restricted and unrestricted reporting of sexual assault." Trainees responded on a scale from 1 to 4; $1=$ not at all effective, $2=$ slightly effective, $3=$ mod erately effective, and $4=$ very effective. Because these questions operationalized "effectiveness" very differently, we did not combine them into a scale. There are downsides to using self-report when evaluating the effectiveness of any training program, but the military routinely uses items such as these to assess and report on the "effectiveness" of its sexual assault prevention efforts. We followed that same procedure here, to determine whether we would reach similar conclusions as the DoD.

\section{Protections Against Common Method Bias}

When assessing experiences of sexual assault and judgments of sexual assault policy, the DoD relies on selfreport, as noted above. This is appropriate for this research domain, because (1) sexual assault typically has no witnesses and goes unreported, (2) when survivors do make reports, that process is often private (unobservable to anyone except the complainant and complaint recipient), and (3) people vary widely in their experiences of institutional response systems. Reliance on single-source, selfreport data raises concerns about common method bias, 
however. When conducting the 2010 WGRA and related surveys, the DoD followed recommendations received in the 1990s from social scientists-most notably, Louise F. Fitzgerald and Fritz Drasgow. Specifically, features were built into the WGRA research design to minimize common method bias ex ante, as recommended by Podsakoff et al. (2003; see also Conway and Lance 2010). First, to reduce evaluation apprehension, participants were assured that their responses would remain confidential, and individually identifying data would never be reported. Second, the surveys assessed sexual assault survivor status independent of training-related measurement, with several pages of items in between; this created "methodological separation" in the measurement of these constructs (Podsakoff et al. 2003, pp. 887-888) and decreased the chances that memories of sexual assault would bias judgments of training. Third, scale endpoints and formats varied across the predictor and criterion variables, which diminished method biases stemming from anchor and endpoint effects. In addition to this array of procedural remedies, we conducted an ex post statistical analysis-the Harman single-factor test-to determine whether common method variance had unduly influenced results. We found no single factor, which argues against a monomethod-bias explanation of results.

\section{Results}

\section{Descriptive Results}

Overall, $2 \%$ of the sample $(n=542)$, or $4 \%$ of women $(n=430)$ and $0.7 \%$ of men $(n=112)$, reported experiencing sexual assault within the last 12 months. Of those sexual assault survivors, a significant majority were women $(79 \%), \chi^{2}(1, N=26,505)=353.24, p<.001$. Additionally, Enlisted personnel ( $86 \%$ of survivors, $n=457$ ) were significantly more likely to have endured sexual assault than Officers (14\% of survivors, $n=77), \chi^{2}(1, N=$ $24,610)=61.40, p<.001$; this was true for both female $\left(\chi^{2}(1, N=10,495)=30.66, p<.001\right)$ and male $\left(\chi^{2}(1\right.$, $N=14,115)=15.13, p<.001)$ Service members. Sexual assault incidence also differed across military Service branch. Past-year sexual assault survivors were more likely to serve in the Army $(32.1 \%, n=174)$ and Marine Corps $(23.2 \%, n=126)$, but less likely to serve in the Air Force $(16.2 \%, n=88)$ and Coast Guard $(6.3 \%, n=34), \chi^{2}(4$, $N=26,505)=43.36, p<.001$; however, this was only true for women, $\chi^{2}(4, n=10,646)=56.27, p<.001$. Among women who were sexually assaulted in the past year, $34 \%(n=146)$ were serving in the Army, $21.9 \%$ $(n=94)$ were in the Marine Corps, $21.6 \%(n=93)$ were in the Navy, $17.2 \%(n=74)$ were in the Air Force, and $5.3 \%(n=23)$ were in the Coast Guard. Among men who
Table 1 Means, standard deviations, and intercorrelations for scales and items

\begin{tabular}{|c|c|c|c|c|c|c|c|}
\hline Variables & Mean (SD) & Range & 1 & 2 & 3 & 4 & 5 \\
\hline 1. Content coverage & $4.49(0.65)$ & $1-5$ & - & & & & \\
\hline $\begin{array}{l}\text { 2. Availability of } \\
\text { information on } \\
\text { reporting }\end{array}$ & $4.16(0.94)$ & $1-5$ & .51 & - & & & \\
\hline $\begin{array}{l}\text { 3. Knowledge of } \\
\text { resources and } \\
\text { protocols }\end{array}$ & $4.30(1.28)$ & $0-6$ & .24 & .28 & - & & \\
\hline $\begin{array}{l}\text { 4. Effective at } \\
\text { reducing/ } \\
\text { preventing sexual } \\
\text { assault }\end{array}$ & $3.30(0.79)$ & $1-4$ & .51 & .33 & .31 & - & \\
\hline $\begin{array}{l}\text { 5. Effective at } \\
\text { explaining } \\
\text { reporting }\end{array}$ & $3.46(0.73)$ & $1-4$ & .60 & .52 & .28 & .66 & - \\
\hline
\end{tabular}

All correlations significant at $p<.001$

$S D$ standard deviation

were sexually assaulted in the past year, $28.6 \%(\mathrm{n}=32)$ were in the Marine Corps, $25 \%(\mathrm{n}=28)$ were serving in the Army, $24.1 \%(\mathrm{n}=27)$ were in the Navy, $12.5 \%$ $(\mathrm{n}=14)$ were in the Air Force, and $9.8 \%(\mathrm{n}=11)$ were in the Coast Guard. See Table 1 for correlations, means, and standard deviations.

\section{Cluster Analysis: Identifying Training Exposure Groups}

We followed a participant-centered approach to examine differences in exposure to sexual assault training. First, all participants who reported having no military training on sexual assault during the last 12 months (9\% of sample; $n=2,112)$ were combined into a No Training group. Next, we used k-means clustering (e.g., Hartigan 1975; MacQueen 1967; Wagstaff et al. 2001) to identify groups among the remaining participants, whose surveys indicated that they had received sexual assault training in the past year. We based this cluster analysis on the ten sexual assault training exposure items, and found three groups. The Comprehensive Training Exposure group (54\% of sample; $n=13,045)$ reported that their sexual assault training was comprehensive, exposing them to a broad range of topics (training exposure scale $M=4.96$, $S D=.11$ ). The Partial Training Exposure group (30\% of sample; $n=7,378$ ) reported that their training had covered some important topics, but missed others $(M=3.99$, $S D=.15)$. Finally, the Minimal Training Exposure group ( $7 \%$ of sample; $n=1,720$ ) reported that their training had missed important topics-painting a picture of incomplete or poor training $(M=2.96, S D=.34)$. 
As a check on the validity of these groups, we conducted an analysis of variance (ANOVA); training exposure group served as the predictor, and the criterion variable was the item assessing satisfaction with information available on sexual assault reporting procedures. For the three exposure groups to differ in a meaningful way, information satisfaction should also differ across the groups. For example, if those in the Comprehensive Exposure group received training that covered more topics than those in the Minimal Exposure group, then Comprehensive Exposure participants should report greater satisfaction with the availability of information on reporting. We found significant group differences for satisfaction reporting $F(2,22,098)=3,583.57, p<.001$. Bonferroni post hoc tests confirmed that personnel in the Comprehensive Exposure group were more satisfied with availability of information $(M=4.58, S D=.75)$ than Partial Exposure $(M=3.84, S D=.81, d=.95)$ and Minimal Exposure personnel $(M=3.24, S D=.93, d=1.60)$. Those in the Partial group were also more satisfied than the Minimal group $(d=.69)$. All differences were significant, $p<.001$. These between-group differences, with large to very large effect sizes, support the validity of the training exposure grouping variable.

\section{Does Training Exposure Predict Accurate Knowledge?}

A key goal of training is to teach accurate knowledge of military resources and protocols surrounding sexual assault. Descriptively speaking, $17.9 \%$ of Service members responded with $100 \%$ accuracy to the six knowledge questions. Conversely, $33.1 \%$ responded with accuracy of $50 \%$ or less (giving correct responses to three or fewer items).

To test our first hypothesis, we conducted an ANOVA with training exposure group (four levels: None, Minimal, Partial, and Comprehensive) as the independent variable and accurate knowledge of resources/protocols as the dependent variable. There were significant differences for knowledge across the four groups, $F(3,18$, $147)=461.93, p<.001$. According to Bonferroni post hoc tests, the Comprehensive Exposure group $(M=4.56$, $S D=1.21$ ) had significantly greater accuracy in their knowledge of resources and protocol than all other groups $(p<.001)$, with an average effect size of $d=.64$. The Partial Exposure group $(M=4.01$, $S D=1.24)$ had significantly greater accuracy than the Minimal Exposure group $(M=3.70, \quad S D=1.38$; $d=.24)$ and No Training group $(M=3.56, S D=1.30$; $d=.35), p<.001$. There were no significant knowledge differences between the No Training and Minimal Exposure groups.
Does Training Exposure Vary by Institutional and Individual Factors?

Next, we conducted a series of Chi Square analyses to test whether sexual assault training exposure differed as a function of military branch (Army, Navy, Marine Corps, Air Force, Coast Guard), rank (Enlisted vs. Officer), gender (women vs. men), or survivor status (past-year sexual assault survivor vs. past-year non-victim). Table 2 contains the actual values, expected values, and proportions across each of the four training groups. Training exposure varied by branch, $\chi^{2}(12, N=24,255)=340.27, p<.001$. Specifically, Service members in the Air Force described the greatest exposure to comprehensive sexual assault training. Conversely, personnel in the Navy, Marine Corps, and Coast Guard reported the least exposure, and Army soldiers fell somewhere in between.

Training exposure also differed by rank, $\chi^{2}$ (3, $N=22,490)=197.63, p<.001$. Officers (compared to Enlisted personnel) were significantly more likely to have received no sexual assault training in the prior year. Additionally, Enlisted personnel were more likely to report both Minimal Exposure and Comprehensive Exposure to training than Officers, whereas Officers were more likely to report that they received Partial Exposure.

As hypothesized, we found significant differences across training groups by gender, $\chi^{2}(3, N=24,255)=26.01$, $p<.001$. Service women were more likely to report that trainings provided Minimal Exposure and Partial Exposure than Service men, and Service men were more likely to report Comprehensive Exposure. We found no gender differences in the No Training group.

There were significant differences across training groups for survivor status, $\chi^{2}(3, N=24,255)=86.73, p<.001$. Past-year sexual assault survivors were more likely to be in the No Training group than past-year non-victims. Additionally, past-year survivors were more likely to report that trainings provided Minimal Exposure compared to nonvictims (who perceived more Comprehensive Exposure). There were no survivor status differences in Partial Exposure.

\section{Do Judgments of Training Effectiveness Vary}

by Institutional and Individual Factors?

Finally, we investigated how perceived training effectiveness differed as a function of Service branch, rank, gender, and survivor status. More specifically, we assessed employees' judgments of training effectiveness on two key outcomes: (1) reducing/preventing sexual assault, and (2) explaining the difference between restricted and unrestricted reporting of sexual assault. In two ANOVAs, branch, rank, gender, and survivor status served as 
Table 2 Training exposure differences by military service/branch, rank, gender, and past-year survivor status

\begin{tabular}{|c|c|c|c|c|c|c|c|c|c|c|c|}
\hline & \multicolumn{5}{|c|}{ Service/branch } & \multicolumn{2}{|l|}{ Rank } & \multicolumn{2}{|l|}{ Gender } & \multicolumn{2}{|c|}{$\begin{array}{l}\text { Past-year survivor } \\
\text { status }\end{array}$} \\
\hline & Army & Navy & $\begin{array}{l}\text { Marine } \\
\text { corps }\end{array}$ & $\begin{array}{l}\text { Air } \\
\text { force }\end{array}$ & $\begin{array}{l}\text { Coast } \\
\text { guard }\end{array}$ & Enlisted & Officer & Women & Men & Survivor & $\begin{array}{l}\text { Non- } \\
\text { victim }\end{array}$ \\
\hline \multicolumn{12}{|c|}{ No training } \\
\hline Count & 479 & 475 & 455 & 483 & 220 & 1,201 & 781 & 870 & 1,242 & 51 & 2,061 \\
\hline Expected & 528.9 & 423.7 & 394.7 & 564.1 & 200.6 & $1,375.7$ & 606.3 & 835.1 & $1,276.9$ & 38.7 & $2,073.3$ \\
\hline $\begin{array}{l}\% \text { Within } \\
\text { column }\end{array}$ & $\begin{array}{l}7.9 \% \\
\mathrm{a}, \mathrm{b}\end{array}$ & $\begin{array}{l}9.8 \% \\
\mathrm{c}\end{array}$ & $\begin{array}{l}10.0 \% \\
\mathrm{c}\end{array}$ & $\begin{array}{l}7.5 \% \\
\mathrm{~b}\end{array}$ & $\begin{array}{l}9.5 \% \\
\text { a, c }\end{array}$ & $\begin{array}{l}7.7 \% \\
\mathrm{a}\end{array}$ & $\begin{array}{l}11.4 \% \\
\text { b }\end{array}$ & $\begin{array}{l}9.1 \% \\
\mathrm{a}\end{array}$ & $\begin{array}{l}8.5 \% \\
\text { a }\end{array}$ & $\begin{array}{l}11.5 \% \\
\text { a }\end{array}$ & $\begin{array}{l}8.7 \% \\
\mathrm{~b}\end{array}$ \\
\hline \multicolumn{12}{|c|}{ Minimal exposure } \\
\hline Count & 397 & 419 & 409 & 326 & 168 & 1,318 & 324 & 724 & 996 & 75 & 1,645 \\
\hline Expected & 430.7 & 345.1 & 321.4 & 459.4 & 163.4 & $1,139.7$ & 502.3 & 680.1 & $1,039.9$ & 31.6 & $1,688.4$ \\
\hline $\begin{array}{c}\% \text { Within } \\
\text { column }\end{array}$ & $\begin{array}{l}6.5 \% \\
\mathrm{a}\end{array}$ & $\begin{array}{l}8.6 \% \\
\mathrm{~b}\end{array}$ & $\begin{array}{l}9.0 \% \\
\mathrm{~b}\end{array}$ & $\begin{array}{l}5.0 \% \\
\mathrm{c}\end{array}$ & $\begin{array}{l}7.3 \% \\
\mathrm{a}, \mathrm{b}\end{array}$ & $\begin{array}{l}8.4 \% \\
\text { a }\end{array}$ & $\begin{array}{l}4.7 \% \\
\mathrm{~b}\end{array}$ & $\begin{array}{l}7.5 \% \\
\mathrm{a}\end{array}$ & $\begin{array}{l}6.8 \% \\
\mathrm{~b}\end{array}$ & $\begin{array}{l}16.9 \% \\
\text { a }\end{array}$ & $\begin{array}{l}6.9 \% \\
\mathrm{~b}\end{array}$ \\
\hline \multicolumn{12}{|c|}{ Partial exposure } \\
\hline Count & 1,843 & 1,591 & 1,433 & 1,668 & 843 & 4,558 & 2,266 & 3,030 & 4,384 & 149 & 7,229 \\
\hline Expected & $1,847.6$ & $1,480.2$ & $1,378.9$ & $1,970.5$ & 700.8 & $4,736.4$ & $2,087.6$ & $2,917.4$ & $4,460.6$ & 135.4 & $7,242.6$ \\
\hline $\begin{array}{c}\% \text { Within } \\
\text { column }\end{array}$ & $\begin{array}{l}30.3 \% \\
\mathrm{a}\end{array}$ & $\begin{array}{l}32.7 \% \\
\mathrm{a}\end{array}$ & $\begin{array}{l}31.6 \% \\
\text { a }\end{array}$ & $\begin{array}{l}25.7 \% \\
b\end{array}$ & $\begin{array}{l}36.6 \% \\
\mathrm{c}\end{array}$ & $\begin{array}{l}29.2 \% \\
\text { a }\end{array}$ & $\begin{array}{l}32.9 \% \\
\text { b }\end{array}$ & $\begin{array}{l}31.6 \% \\
\text { a }\end{array}$ & $\begin{array}{l}29.7 \% \\
b\end{array}$ & $\begin{array}{l}33.5 \% \\
\text { a }\end{array}$ & $\begin{array}{l}30.4 \% \\
\text { a }\end{array}$ \\
\hline \multicolumn{12}{|c|}{ Comprehensive exposure } \\
\hline Count & 3,355 & 2,381 & 2,236 & 4,001 & 1,072 & 8,533 & 3,509 & 4,967 & 8,078 & 170 & 12,875 \\
\hline Expected & $3,266.8$ & $2,617.1$ & $2,438.0$ & $3,484.0$ & $1,239.2$ & $8,358.2$ & $3,683.8$ & $5,158.3$ & $7,886.7$ & 239.3 & $12,805.7$ \\
\hline $\begin{array}{l}\% \text { Within } \\
\text { column }\end{array}$ & $\begin{array}{l}55.2 \% \\
\text { a }\end{array}$ & $\begin{array}{l}48.9 \% \\
\text { b }\end{array}$ & $\begin{array}{l}49.3 \% \\
b\end{array}$ & $\begin{array}{l}61.8 \% \\
\mathrm{c}\end{array}$ & $\begin{array}{l}46.5 \% \\
b\end{array}$ & $\begin{array}{l}54.7 \% \\
\mathrm{a}\end{array}$ & $\begin{array}{l}51.0 \% \\
\mathrm{~b}\end{array}$ & $\begin{array}{l}51.8 \% \\
\text { a }\end{array}$ & $\begin{array}{l}55.1 \% \\
\mathrm{~b}\end{array}$ & $\begin{array}{l}38.2 \% \\
\mathrm{a}\end{array}$ & $\begin{array}{l}54.1 \% \\
\mathrm{~b}\end{array}$ \\
\hline
\end{tabular}

Within each training group, a different subscript indicates column proportions significantly differ from each other at $p \leq .05$

predictors, and the two perceived effectiveness variables served as criterion variables. To explore the possibility that gender and survivor status may interact in predicting these judgments, we also entered a gender $\mathrm{X}$ survivor status interaction term. Due to the large discrepancy in the number of past-year survivors $(n=430$ women and 112 men) and past-year non-victims $(n=10,216$ women and 15,747 men), we selected a random sample of 500 female and 500 male past-year non-victims to create a more balanced design for this analysis. We probed differences using Bonferroni pairwise comparisons.

When predicting judgments of training effectiveness at reducing/preventing sexual assault, the main effect of Service branch was significant, $F(4,1,228)=2.55$, $p=.04$. We observed the following mean differences (ordered highest to lowest): Air Force $(M=3.26$, $S D=.79)$, Marine Corps $(M=3.13, S D=.86)$, Navy $(M=3.08, \quad S D=.91)$, Army $(M=3.01, \quad S D=.92)$, Coast Guard $(M=2.99, S D=1.03)$. Service members in the Air Force judged training to be more effective than those in the Army $(p=.002, d=.29)$ and Coast Guard $(p=.01, d=.30)$. The main effect of rank was significant, $F(1,1,228)=6.33, p=.01$. Enlisted personnel
$(M=3.13, S D=.90)$ perceived the training to be more effective at actually reducing/preventing sexual assault than Officers $(M=3.07, S D=.82), p=.01$; this effect, however, was small in magnitude, $d=.07$. The main effect of gender was also significant, $F(1,1,228)=10.19$, $p<.001$. Service men $(M=3.28, S D=.83)$ perceived the training to be more effective at reducing/preventing sexual assault than Service women $(M=3.01, S D=.90)$, $p<.001, d=.31$. Additionally, there was a significant main effect of survivor status, $F(1,1,228)=23.27$, $p<.001$. As expected, past-year non-victims $(M=3.27$, $S D=.79)$ believed that training was more effective at actually reducing/preventing sexual assault than those who had experienced sexual assault in the past year $(M=2.80$, $S D=.99), p<.001, d=.53$.

At the same time, there was a significant interaction between gender and survivor status, $F(1,1,228)=4.27$, $p=.04$. As depicted in Fig. 1, male past-year non-victims $(M=3.32, S D=.81)$ perceived military training to be more effective at reducing/preventing sexual assault than both male past-year survivors $[M=3.01, S D=.95$; $t(496)=2.92, p=.001, d=.35]$ and female past-year survivors $[M=2.74, S D=.98, t(736)=8.80, p<.001$, 


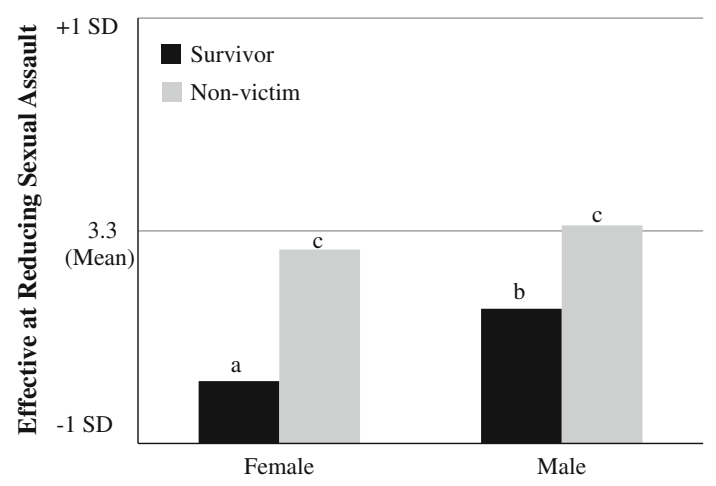

Fig. 1 Interaction between gender and past-year survivor status predicting perceptions that training is effective at reducing/preventing sexual assault. A different subscript indicates that groups significantly differ at $p<.05$

$d=.65]$. Similarly, female past-year non-victims $(M=3.23, S D=.77)$ perceived training to be more effective than both male past-year survivors $(t(497)=2.17, p=.03, d=.26)$ and female past-year survivors $(t(764)=7.75, p<.001, d=.56)$. However, female compared to male past-year survivors were less likely to believe that training was effective, $t(411)=2.15$, $p=.03, d=.28$. Male and female past-year non-victims did not differ in their judgments, $t(822)=1.64, p=.10$.

When predicting judgments of training effectiveness at explaining the difference between restricted and unrestricted reporting, we again found a significant main effect of Service branch, $F(4,1,224)=4.31, p=.002$. Air Force personnel $(M=3.50, S D=.72)$ perceived training to be significantly more effective at explaining reporting options than the Marines $(M=3.26, S D=.82, p=.02, d=.31)$ and Coast Guard $(M=3.15, S D=1.00, \quad p=.01$, $d=.41)$. There were no significant differences for either the Navy $(M=3.27, S D=.89)$ or Army $(M=3.29$, $S D=.86)$. We found no main effect of rank, $F(1$, $1,224)=0.88, p=.35$. That is, there were no significant differences between Officers' $(M=3.34, S D=.81)$ and Enlisted personnel's $(M=3.32, S D=.85)$ judgments that training was effective at explaining the reporting options. There was a significant main effect of gender, $F(1$, $1,224)=4.72, p=.03$. Women $(M=3.26, S D=.85)$ perceived training to be less effective than men $(M=3.42$, $S D=.81), p=.03, d=.19$. We also found a significant main effect of survivor status, $F(1,1,224)=19.19$, $p<.001$. Past-year sexual assault survivors $(M=3.09$, $S D=.96)$ found training less effective at explaining the difference between reporting options than past-year nonvictims $(M=3.44, S D=.75), p<.001, d=.41$. There was no interaction between gender and survivor status $F(1,1,224)=1.98, p=.16$.

\section{Discussion}

Sexual assault is an insidious problem in the military work environment, one that is disproportionately targeted against women by men (Bell and Reardon 2011; Martin et al. 2000). Within the last decade, the DoD has made public efforts to address the problem of sexual assault. The new (as of 2005) SAPRO centralizes responsibility for sexual assault training. However, these latest sexual assault training efforts have undergone little empirical evaluation by outside researchers. This was our goal.

First, we examined past-year exposure to sexual assault training. Research by the U.S. Government Accountability Office (GAO 2012) concluded that a majority of Service members do receive sexual assault training. Similarly, Kelley et al. (2005) evaluated the Navy's Sexual Assault Victim Intervention (SAVI) program, and reported that a majority of participants were satisfied with training. These studies, however, did not delve deeply into how mисh training personnel received, whether it was comprehensive, and whether training experiences varied across key demographic subgroups. Most problematically, gender was not given sufficient consideration. The U.S. military is over $85 \%$ male, so any statistic that collapses across gender privileges experiences of men over women. Given that only $1-2 \%$ of Service men endure sexual assault (Bostock and Daley 2007; Lipari et al. 2008; Street et al. 2008), this foregrounds the perspective of military members at low risk for being targeted with this act of violence.

In the current project, we found that approximately $93 \%$ of participants had received military training on topics related to sexual assault within the last year. At first glance, this is reassuring, but closer analyses revealed variation in reported training content across trainees. Approximately $54 \%$ of trainees described what amounts to "comprehensive" content coverage in their training, addressing sexual assault actions, interventions, reporting mechanisms, and resources. However, $30 \%$ described sexual assault training that, in our judgment, was "partial" in that it missed critical topics. Another $7 \%$ of trainees reported that the training they had undergone missed many content domains, painting a picture of "minimal" coverage. Granted, these are subjective trainee-reported measures, and most likely some trainees had forgotten exactly what their training covered (which is problematic in and of itself, suggesting a need for post-training refreshers). Still, if we follow standard military practice and take trainee accounts at face value, what does their training exposure predict in terms of key outcomes?

Prior research suggests that Service members' experiences of sexual assault training relate to important personal and professional outcomes. For instance, positive perceptions of the Navy's sexual assault training program 
predicted better quality of life and job readiness (Kelley et al. 2005). We investigated relationships between training exposure and accurate knowledge of sexual assault resources and protocols in the military (e.g., do employees know that they can report unwanted sexual touching that does not result in "completed" rape?). We found that personnel in the Comprehensive Exposure group, who described their training as covering a broad range of topics, had significantly greater knowledge of sexual assault resources and protocols than trainees who reported that they had been exposed to only partial or minimal content. Moreover, trainees reporting Minimal Exposure had no more knowledge of resources and protocols than those who had received no training at all. Thus, receiving deficient training may be as problematic as going untrained.

This finding carries important implications. Survivors of sexual assault are already at risk for experiencing adverse personal and professional consequences as a result of the trauma; lack of access to comprehensive sexual assault training could further exacerbate their distress. Inadequate training may leave victims unsure of their rights and options, and potential responders (e.g., Commanding Officers) unsure of how to manage the situation. Absent adequate training with respect to the causes, experiences, and outcomes of sexual assault, leadership will lack the knowledge necessary to help survivors emotionally, professionally, and legally. Deficient training could also perpetuate an institutional culture that is ignorant or tolerant of sexual assault. An organizational context that even informally tolerates sexualized violence can affect the incidence of sexual assault (Firestone et al. 2012). Without proper instruction, past and future offenders may not realize the criminality of their actions. For example, they may not know that sexual intercourse with a person too intoxicated to give meaningful consent is a form of rape under military (and civilian) law.

Sexual assault training is mandated for all Service members and command staff (U. S. GAO 2012; Hillman 2009). However, our results found that training exposure varies by both institutional and individual factors. Our results suggest that Air Force personnel had the greatest access to comprehensive sexual assault training. Conversely, those in the Navy, Marine Corps, and Coast Guard reported the least access to training and, when trained, the lowest content exposure. It is interesting to compare this to sexual assault incidence rates: a lower proportion of assault survivors were serving in the Air Force than the Marine Corps (a pattern consistent with past research, e.g., Hay and Elig 1999). Thus, the Service branch (Air Force) that stands out as exposing its members to the most comprehensive sexual assault training also has some of the lowest rates of sexual assault. Though our research cannot speak to causality, it is possible that military sexual assault training may help reduce sexual assault, but only if it is comprehensive.

We further found that Officers were less likely to receive sexual assault training (in the past year) than Enlisted personnel, and were more likely to describe training content coverage as partial. Officers may have greater experience with sexual assault training over the course of their military careers, but in recent years (1) the DoD has substantively modified its sexual assault response procedures, and (2) the Uniform Code of Military Justice has altered its treatment of "rape, sexual assault, and other sexual misconduct." Officers must receive training on the new sexual assault protocols, resources, and laws. Also, in the military work environment, Officers are often the first point of contact when survivors elect to report their sexual assault. Thus, it is discouraging how many Officers reported either no recent exposure to sexual assault training of any kind, or exposure to training that was incomplete, missing topics that are critical for report recipients to know.

Nevertheless, it is a definite strength of the military's training program that most newly enlisted Service members were educated on sexual assault. One study found that men with a history of perpetrating sexual violence (premilitary) were almost 10 times more likely to attempt or commit rape during their first year of military service (McWhorter et al. 2008). Prior research also suggests that lower-ranking Service members are at greater risk for being victimized (Harned et al. 2002), a finding that we replicated, with a greater proportion of Enlisted personnel than Officers being survivors of military sexual assault in the past year. Providing training to all newly enlisted Service women and men helps ensure that they understand the military's zero-tolerance policy on sexual assault, the consequences imposed on assailants, and the resources available to survivors (Bell and Reardon 2011; Kelley et al. 2005). However, it is crucial for sexual assault training to continue throughout Service members' military careers. Post-training activities and refreshers strengthen the effectiveness of training programs (Perry et al. 2010).

Service women were more likely than Service men to describe the coverage of content in sexual assault training as lacking. Though this finding is based entirely on selfreport, there is good reason to trust women's claims around this issue. Women endure a greater amount of sexual violence than men, in both military and civilian life (Bostock and Daley 2007); as a result, women may (1) have more knowledge about this issue prior to training, (2) attend more closely to training, and (3) retain more knowledge from the training-enabling them to describe its content more accurately later. The same goes for survivors of sexual assault (both female and male), and pastyear survivors also described training as minimal in its content coverage. 
In fact, past-year survivors were overrepresented among personnel reporting no sexual assault training in the prior year. Military sexual assault training often follows a group format (e.g., U.S. GAO 2008), so if one person has gone untrained, the same may be true of her/his entire workgroup or unit. This may increase the chance that someone in the group sexually assaults her/him. We were unable to test this hypothesis directly, as the WGRA does not collect the data necessary to identify workgroups or units. This precludes multi-level analyses (e.g., we could not test whether absence of training at the group level predicts sexual assault at the individual level); however, this is a "testable" possibility for future research.

Our final aim was to investigate training "effectiveness," using Service member judgments, a standard practice in the military that can offer valuable insight (Sackett and Mullen 1993). The DoD's 2010 annual report on sexual assault in the military concluded that "most Active Duty members receive effective training on sexual assault" (p. 104). However, our results question this sweeping assertion. We found wide variation in judgments of how effective training was at: (1) actually reducing/preventing sexual assault, and (2) explaining the difference between restricted and unrestricted reporting.

For instance, Service members in the Air Force perceived training to be significantly more effective than personnel in other Service branches. As discussed above, Air Force personnel reported the greatest access to comprehensive sexual assault training as well. The SAPRO requires each Military Service to maintain its own training program (Department of Defense 2010), and our results suggest that some Service branches may be more successful in this effort than others. In addition, Officers were less likely than Enlisted personnel to believe that training is effective at preventing sexual assault. Given their relative organizational power, and the military's procedure for unrestricted reporting, it is likely that many Officers had greater knowledge of the frequency of sexual assaults (Hillman 2009; Turchik and Wilson 2010). Moreover, Officers are likely to have served for a longer period of time, which may provide more insight into changes, or lack thereof, in the frequency of sexual assault after training was widely implemented. As expected, we found that women and past-year sexual assault survivors (and, especially, female survivors) were less likely to judge training as effective at reducing/preventing sexual assault and explaining reporting options (i.e., the difference between "restricted" and "unrestricted" reporting) compared to men and past-year non-victims.

These results suggest that the conclusion made in the DOD's 2010 Annual Report on Sexual Assault-that training is "effective" because a "majority" of Service members agree — is a vast overgeneralization. Most military personnel are men who will never face (or even fear) sexual assault. Given their sheer numbers, the perspectives of male-non-victims are weighted more heavily than other perspectives. In other words, these sweeping conclusions minimize the voices of potential and past victims. Future evaluations of military sexual assault training effectiveness should focus more on the perspectives of those who have been, and are more likely to be, affected by sexual violence. However, future evaluations should also examine if training affects, and hopefully decreases, sexually aggressive behavior among potential perpetrators.

Prior research finds that experiencing sexual violence in a military context may be more damaging to mental and physical health than in other environments (Himmelfarb et al. 2006). The perpetrator is frequently a fellow member of the organization, and the victim must often continue living and working alongside her/his assailant (Bell and Reardon 2011). Furthermore, the military culture of loyalty and self-sufficiency may hinder the victim's ability to seek help and increase the victim's distress if assaulted by a military member who was trusted and relied upon (Bell and Reardon 2011). Women may be at an even greater risk because they are substantially more likely than men to be sexually assaulted while on active duty. Perceived institutional and social support can mitigate some of the devastating consequences of sexual assault (Campbell 2006; Campbell et al. 2001a; David et al. 2006; Martin et al. 2000; Ullman 1999; Ullman and Filipas 2001); however, we found that Service women and men who recently survived a sexual assault received inadequate information about reporting. It is likely that survivors have given more thought to and/or actually made use of reporting procedures, so their views on training are especially valuable (and, in the present study, deeply troubling).

\section{Limitations and Future Directions}

Like all projects, this study has its limitations. Our secondary analysis of cross-sectional, correlational data did not allow us to establish causal relationships or assess change over time. Additionally, it would have been beneficial to consider participants' length of military service (not assessed in the 2010 WGRA) in our assessments of training experiences. Examining whether sexual assault survivors had actually made a restricted or unrestricted report, and survivors' satisfaction with reporting experiences, would have added to our analysis of training effectiveness; this information was collected in the 2010 WGRA, but was "removed to preserve confidentiality" in the publicly available dataset (DMDC 2010, p. 23). There are limitations to consider with the measures as well. For instance, the measure of sexual assault only asked about experiences in the past year. Given the high rates of sexual 
assault in the military, it is likely that many of the "nonvictims" had experienced sexual assault at some point in their military career. Thus, the dichotomous measure of survivor status (past-year survivor vs. past-year non-victim) will have missed experiences of military sexual assault. The items assessing training exposure and effectiveness were also highly subjective. More objective measures (e.g., evaluating the content of training programs, counting the hours of training each Service member received) would have improved our assessment of training exposure. Similarly, subjective measures of training effectiveness only provide a partial picture of effectiveness. For example, we were unable to make causal conclusions about the effect of training on actual rates of sexual assault.

These limitations notwithstanding, there are many strengths of this study. The data come from a very large organizational sample $(N>24,000)$, representing all branches of the U.S. Armed Forces, both Enlisted and Officer ranks, with women and personnel of color oversampled to ensure diversity. This study provides a detailed look (not available elsewhere) at how military sexual assault trainings are received and perceived. Many interesting lines of inquiry can grow out of this project. For instance, future research should ideally employ experimental methods to evaluate training. A study by Rau et al. (2010) evaluated the effectiveness of the Navy Sexual Assault Intervention Training (SAIT) program for men, and found that training increased rape knowledge and empathy for rape victims, and reduced rape myth acceptance. These attitudinal changes were greatest among men with no prior history of sexually coercive behavior (Rau et al. 2010). The results of that study are encouraging, but additional investigation is needed to assess the long-term effects of training and the effectiveness of follow-up trainings.

In addition, research should consider unanticipated negative outcomes of training. For instance, is gendersegregated sexual assault training (e.g., SAIT) more effective than mixed-gender training, or does it perpetuate harmful myths about women as weak, vulnerable, or victimized (Hillman 2009)? Some studies of sexual assault training on college campuses suggest benefits of samegender training groups (e.g., Brecklin and Forde 2001), but others find positive results with mixed-gender groups (e.g., Anderson and Whiston 2005). As these findings suggest, training content and delivery are not always one and the same. Future assessments of military sexual assault training should consider the gender makeup of training groups. Further, although the SAPRO was designed to centralize sexual assault trainings and victim advocacy services, our results suggest that training exposure can vary widely. Thus, future research should endeavor to understand how each Service branch conducts training, both in terms of content and mode of delivery.

Future studies should also evaluate the specific content of military sexual assault training programs. Items in the WGRA (e.g., "teaches how to avoid situations that might increase the risk of being a victim of sexual assault") suggest an emphasis on victim precipitation in training. This effectively places the burden of responsibility on victims rather than assailants, potentially eroding support for survivors and exacerbating self-blame (Cass 2007). Trainings that emphasize organizational/social factors and challenge common rape myths may be more effective (e.g., Cass 2007; Lonsway 1996; Lonsway et al. 2001).

\section{Conclusion}

In line with a social-ecological perspective, sexual assault research must carefully consider the role of context (Campbell et al. 2009). By accounting for individual factors, organizational features, military community context, and the current political climate, we discovered important nuances in military sexual assault training. It has been almost ten years since the DoD created the SAPRO, and the U.S. GAO has called for systematic evaluation of SAPRO training programs. The results of the current study heed this call. Exposure to comprehensive training predicted lower incidence of sexual assault and superior knowledge of military sexual assault resources and protocols. This suggests that military sexual assault training, when done right, can be effective. Rates of exposure and judgments of effectiveness, however, vary widely across this community. Taken together, our results cast doubt on recent military assertions that "most" members of the U.S. Armed Forces receive "effective" training on sexual assault.

Acknowledgments We thank Abigail J. Stewart for her feedback on an earlier draft of this article. The Defense Manpower Data Center (DMDC) conducted the 2010 survey analyzed here, as part of the quadrennial cycle of human relations surveys outlined in Title $10 \mathrm{U}$. S. Code Section 481.

\section{References}

Anderson, L. A., \& Whiston, S. C. (2005). Sexual assault education programs: A meta-analytic examination of their effectiveness. Psychology of Women Quarterly, 29(4), 374-388. doi:10.1111/j. 1471-6402.2005.00237.x.

Bachman, R., \& Taylor, B. H. (1994). The measurement of family violence and rape by the redesigned National Crime Victimization Survey. Justice Quarterly, 11(3), 499-512. doi:10.1080/ 07418829400092371.

Bell, M. E., \& Reardon, A. (2011). Experiences of sexual harassment and sexual assault in the military among OEF/OIF veterans: 
Implications for health care providers. Social Work in Health Care, 50(1), 34-50. doi:10.1080/00981389.2010.513917.

Benedict, H. (2010). The lonely soldier: The private war of women serving in Iraq. Boston: Beacon Press.

Bostock, D. J., \& Daley, J. G. (2007). Lifetime and current sexual assault and harassment victimization rates of active-duty United States Air Force women. Violence Against Women, 13(9), 927-944. doi:10.1177/1077801207305232.

Brecklin, L. R., \& Forde, D. R. (2001). A meta-analysis of rape education programs. Violence and Victims, 16(3), 303-321.

Breitenbecher, K. H. (2000). Sexual assault on college campuses: Is an ounce of prevention enough? Applied and Preventive Psychology, 9(1), 23-52. doi:10.1016/S0962-1849(05)80036-8.

Campbell, R. (2005). What really happened? A validation study of rape survivors' help-seeking experienced with the legal and medical systems. Violence and Victims, 20(1), 55-68.

Campbell, R. (2006). Rape survivors' experiences with the legal and medical systems: Do rape victim advocates make a difference? Violence Against Women, 21, 30-45. doi:10.1177/1077801205 277539.

Campbell, R. (2008). The psychological impact of rape victims' experiences with the legal, medical, and mental health systems. American Psychologist, 63(8), 702-717. doi:10.1037/0003066X.63.8.702.

Campbell, R., Ahrens, C. E., Sefl, T., Wasco, S. M., \& Barnes, H. E. (2001a). Social reactions to rape victims: Healing and hurtful effects on psychological and physical health outcomes. Violence and Victims, 16(3), 287-302.

Campbell, R., Dworkin, E., \& Cabral, G. (2009). An ecological model of the impact of sexual assault on women's mental health. Trauma, Violence, \& Abuse, 10, 225-246. doi:10.1177/ 1524838009334456 .

Campbell, R., \& Raja, S. (2005). The sexual assault and secondary victimization of female veterans: Help-seeking experiences with military and civilian social systems. Psychology of Women Quarterly, 29(1), 97-106. doi:10.1111/j.1471-6402.2005.00171. $\mathrm{x}$.

Campbell, R., Sefl, T., Barnes, H. E., Ahrens, C. E., Wasco, S. M., \& Zaragoza-Diesfeld, Y. (1999). Community services for rape survivors: Enhancing psychological well-being or increasing trauma? Journal of Consulting and Clinical Psychology, 67, 847-858. doi:10.1037/0022-006X.67.6.847.

Campbell, R., Wasco, S. M., Ahrens, C. E., Sefl, T., \& Barnes, H. E. (2001b). Preventing the "second rape": Rape survivors' experiences with community service providers. Journal of Interpersonal Violence, 16, 1239-1259. doi:10.1177/0886260010160 12002.

Cass, A. I. (2007). Routine activities and sexual assault: An analysis of individual-and school-level factors. Violence and Victims, 22(3), 350-366. doi:10.1891/088667007780842810.

Conway, J. M., \& Lance, C. E. (2010). What reviewers should expect from authors regarding common method bias in organizational research. Journal of Business and Psychology, 25, 325-334. doi:10.1007/s10869-010-9181-6.

David, W. S., Simpson, T. L., \& Cotton, A. J. (2006). Taking charge: A pilot curriculum of self-defense and personal safety training for female veterans with PTSD because of military sexual trauma. Journal of Interpersonal Violence, 21, 555-565. doi:10. $1177 / 0886260505285723$

Defense Manpower Data Center. (2010). 2010 Workplace and gender relations survey of active duty members: Administration, datasets, and codebook. (Report No. 2010-027). Arlington, VA: Author.

Defense Manpower Data Center. (2013a). 2012 Workplace and gender relations survey of active duty members: Survey note. (Note No. 2013-007). Arlington, VA: Author.
Defense Manpower Data Center. (2013b). Armed Forces strength figures for August 31, 2013. Retrieved from https://www.dmdc. osd.mil/appj/dwp/reports.do?category=reports\&subCat=milAct DutReg.

Delphy, C. (1993). Rethinking sex and gender. Women's Studies International Forum, 16(1), 1-9.

Department of Defense. (2009). Report to the council on women and girls. Washington, DC: Government Printing Office.

Department of Defense. (2010). Department of defense annual report on sexual assault in the military. Retrieved from http://service women.org/SAPRO\%20Reports/DoD_Fiscal_Year_2010_Annual_ Report_on_Sexual_Assault_in_the_Military.pdf.

Department of Defense. (2013). Sexual assault prevention and response (SAPR) program procedures. Retrieved from http:// www.dtic.mil/whs/directives/corres/pdf/649502p.pdf.

Department of Defense Sexual Assault Prevention and Response Office (n.d.) Mission and history. Retrieved from http://www. sapr.mil/.

DuMont, J., White, D., \& McGregor, M. J. (2009). Investigating the medical forensic examination from the perspectives of sexually assaulted women. Social Science and Medicine, 68(4), 774-780. doi:10.1016/j.socscimed.2008.11.010.

Eagly, A. H., \& Karau, S. J. (2002). Role congruity theory of prejudice toward female leaders. Psychological Review, 109(3), 573-598. doi:10.1037/0033-295X.109.3.573.

Felson, R. B., \& Pare, P. (2008). Gender and the victim's experience with the criminal justice system. Social Science Research, 37(1), 202-219. doi:10.1016/j.ssresearch.2007.06.014.

Firestone, J. M., Miller, J. M., \& Harris, R. (2012). Implications for criminal justice from the 2002 and 2006 Department of Defense gender relations and sexual harassment surveys. American Journal of Criminal Justice, 37(3), 432-451. doi:10.1007/ s12103-010-9085-z.

Fontana, A., \& Rosenheck, R. (1998). Focus on women: Duty-related and sexual stress in the etiology of PTSD among women veterans who seek treatment. Psychiatric Services, 49(5), 658-662.

Harman, J. (2008). Finally, some progress in combating rape and assault in the military. The Huffington Post. Retrieved from http://www.huffingtonpost.com/rep-jane-harman/finally-someprogress-in_b_125504.html.

Harned, M. S., Ormerod, A. J., Palmieri, P. A., Collinsworth, L. L., \& Reed, M. (2002). Sexual assault and other types of sexual harassment by workplace personnel: A comparison of antecedents and consequences. Journal of Occupational Health Psychology, 7(2), 174-188. doi:10.1037/1076-8998.7.2.174.

Harris, M. B., \& Miller, K. C. (2000). Gender and perceptions of danger. Sex Roles, 43(11-12), 843-863.

Hartigan, J. A. (1975). Clustering algorithms. New York: Wiley.

Hay, M. S., \& Elig, T. W. (1999). The 1995 Department of Defense sexual harassment survey: Overview and methodology. Military Psychology, 77, 233-242. doi:10.1207/s15327876mp1103_2.

Heilman, M. E., \& Eagly, A. H. (2008). Gender stereotypes are alive, well, and busy producing workplace discrimination. Industrial and Organizational Psychology, 1(4), 393-398. doi:10.1111/j. 1754-9434.2008.00072.x.

Hillman, E. L. (2009). Front and center: Sexual violence in U.S. military law. Politics \& Society, 37(1), 101-129. doi:10.1177/ 0032329208329753.

Himmelfarb, N., Yaeger, D., \& Mintz, J. (2006). Posttraumatic stress disorder in female veterans with military and civilian sexual trauma. Journal of Traumatic Stress, 19(6), 837-846. doi:10. 1002/jts.20163.

Kang, H., Dalager, N., Mahan, C., \& Ishii, E. (2005). The role of sexual assault on the risk of PTSD among gulf war veterans. Annals of Epidemiology, 15(3), 191-195. doi:10.1016/j.annepi dem.2004.05.009. 
Kelley, M. L., Schwerin, M. J., Farrar, K. L., \& Lane, M. S. (2005). An evaluation $\mathrm{f}$ a sexual assault prevention and advocacy program for U.S. Navy personnel. Military Medicine, 170, 320-326.

Kilpatrick, D. G., Edmunds, C. N., \& Seymour, A. K. (1992). Rape in America: A report to the nation. Arlington, VA: National Victim Center.

Kimerling, R., Gima, K., Smith, M. W., Street, A., \& Frayne, S. (2007). The Veterans Health Administration and military sexual trauma. American Journal of Public Health, 97(12), 2160-2166. doi:10.2105/AJPH.2006.092999.

Lipari, R. N., Cook, P. J., Rock, L. M., \& Matos, K. (2008). 2006 Gender relations survey of active duty members. Arlington, VA: Department of Defense Manpower Data Center.

Lonsway, K. A. (1996). Preventing acquaintance rape through education: What do we know? Psychology of Women Quarterly, 20(2), 229-265.

Lonsway, K. A., Welch, S., \& Fitzgerald, L. F. (2001). Police training in sexual assault response process, outcomes, and elements of change. Criminal Justice and Behavior, 28(6), 695-730.

MacQueen, J. B. (1967). Some methods for classification and analysis of multivariate observations. Proceedings of the fifth symposium on math, statistics, and probability (pp. 281-297). Berkeley, CA: University of California Press.

Martin, L., Rosen, L. N., Durand, D. B., Knudson, K. H., \& Stretch, R. H. (2000). Psychological and physical health effects of sexual assaults and nonsexual traumas among male and female United States Army soldiers. Behavioral Medicine, 26(1), 23-33. doi:10.1080/08964280009595750.

McWhorter, S. K., Stander, V. A., Merrill, L. L., Thomsen, C. J., \& Milner, J. S. (2008). Reports of rape reperpetration by newly enlisted male Navy personnel. Violence and Victims, 24(2), 204-218. doi:10.1891/0886-6708.24.2.204.

Morris, M. (1996). By force of arms: Rape, war, and military culture. Duke Law Journal, 45(4), 652-781. doi:10.2307/1372997.

Oakley, A. (1972/1985). Sex, gender, and society. London: Temple Smity (revised edition, 1985, Gower)

Pardue, D., \& Moniz, D. (1996). The State, p. A8.

Perry, E. L., Kulik, C. T., Bustamante, J., \& Golom, F. D. (2010). The impact of reason for training on the relationship between "best practices" and sexual harassment training effectiveness. Human Resource Development Quarterly, 21, 187-208. doi:10.1002/ hrdq.20043.

Podsakoff, P. M., MacKenzie, S. B., Lee, J. Y., \& Podsakoff, N. P. (2003). Common method biases in behavioral research: A critical review of the literature and recommended remedies. Journal of Applied Psychology, 88, 879-903. doi:10.1037/00219010.88.5.879.

Rau, T., Merrill, L., McWhorter, S., Stander, V., Thomsen, C., Dyslin, C. et al. (2010). Evaluation of a sexual assault education/ prevention program for male U.S. Navy personnel. Military Medicine, 175(6), 429-434.

Rock, L. M., Lipari, R. N., Cook, P. J., \& Hale, A. D. (2011). 2010 Workplace and gender relations survey of active duty members: Overview report on sexual harassment. DMDC Report No. 2010. Arlington, VA: Defense Manpower Data Center.

Sackett, P. R., \& Mullen, E. J. (1993). Beyond formal experimental design: Towards an expanded view of the training evaluation process. Personnel Psychology, 46(3), 613-627. doi:10.1111/j. 1744-6570.1993.tb00887.x.

Sadler, A. G., Booth, B. M., Cook, B. L., \& Doebbeling, B. N. (2003). Factors associated with women's risk of rape in the military environment. American Journal of Industrial Medicine, 44(1), 262-273. doi:10.1002/ajim.10202.

Sadler, A. G., Booth, B. M., Nielson, D., \& Doebbeling, B. N. (2000). Health-related consequences of physical and sexual violence: women in the military. Obstetrics and Gynecology, 96(3), 473-480. doi:10.1016/S0029-7844(00)00919-4.

Schmid, M. N. (2010). Combating a different enemy: Proposals to change the culture of sexual assault in the military. Villanova Law Review, 55(2), 475-508.

Scott, J. (1988). Gender and the politics of history. New York: Columbia University Press.

Sims, C. S., Drasgow, F., \& Fitzgerald, L. F. (2005). The effects of sexual harassment on turnover in the military: Time-dependent modeling. Journal of Applied Psychology, 9(6), 1141-1152. doi:10.1037/0021-9010.90.6.1141.

Spence, J. T., \& Helmreich, R. L. (1980). Masculine instrumentality and feminine expressiveness: Their relationships with sex role attitudes and behaviors. Psychology of Women Quarterly, 5(2), 147-163. doi:10.1111/j.1471-6402.1980.tb00951.x.

Street, A. E., Stafford, J., Mahan, C. M., \& Hendricks, A. (2008). Sexual harassment and assault experienced by reservists during military service: Prevalence and health correlates. Journal of Rehabilitation Research and Development, 45(3), 409-420. doi:10.1682/JRRD.2007.06.0088.

Surís, A., Lind, L., Kashner, T. M., Borman, P. D., \& Petty, F. (2004). Sexual assault in women veterans: An examination of PTSD risk, health care utilization, and cost of care. Psychosomatic Medicine, 66(5), 749-756. doi:10.1097/01.psy.0000138117.58559.7b.

Tailhook Association. (n.d.). About us. Retrieved from http://www. tailhook.net/.

Turchik, J. A., \& Wilson, S. M. (2010). Sexual assault in the U.S. military: A review of the literature and recommendations for the future. Aggression and Violent Behavior, 15(4), 267-277. doi:10. 1016/j.avb.2010.01.005.

Ullman, S. E. (1999). Social support and recovery from sexual assault: A review. Aggression and Violent Behavior, 4, 343-358. doi:10.1016/S1359-1789(98)00006-8.

Ullman, S. E., \& Filipas, H. H. (2001). Predictors of PTSD symptom severity and social reactions in sexual assault victims. Journal of Traumatic Stress, 14, 369-389. doi:10.1023/A:1011125220522.

Ullman, S. E., \& Townsend, S. M. (2007). Barriers to working with sexual assault survivors a qualitative study of rape crisis center workers. Violence Against Women, 13(4), 412-443. doi:10.1177/ 1077801207299191.

U.S. Government Accountability Office. (2008). Military personnel: 's and the Coast Guard's sexual assault prevention and response programs face implementation and oversight challenges. Retrieved from http://www.gao.gov/new.items/d08924.pdf.

U.S. Government Accountability Office. (2012). Military personnel: Prior GAO work on DOD's actions to prevent and respond to sexual assault in the military. Retrieved from http://www.gao. gov/products/GAO-12-571R.

USA Today. (2013). Fort hood assault prevention chief under investigation. Retrieved from http://www.usatoday.com/story/ news/nation/2013/05/14/fort-hood-sexual-assault-pentagoninvestigation-prostitution/2159685/.

Wagstaff, K., Cardie, C., Rogers, S., \& Schroedl, S. (2001). Constrained k-means clustering with background knowledge. In Proceedings of the eighth international conference on machine learning, pp. 577-584.

Ziering, A., \& Barklow, T. K., \& Dick, K. (2012). The invisible war [Motion picture]. United States: Chain Camera Pictures. 